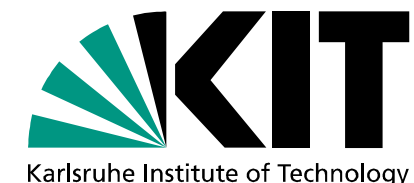

\title{
Energy autonomy in residential buildings: a techno-economic model- based analysis of the scale effects
}

\author{
Russell McKenna, Erik Merkel, Wolf Fichtner
}

No. 12 | February 2016

\section{WORKING PAPER SERIES IN PRODUCTION AND ENERGY}
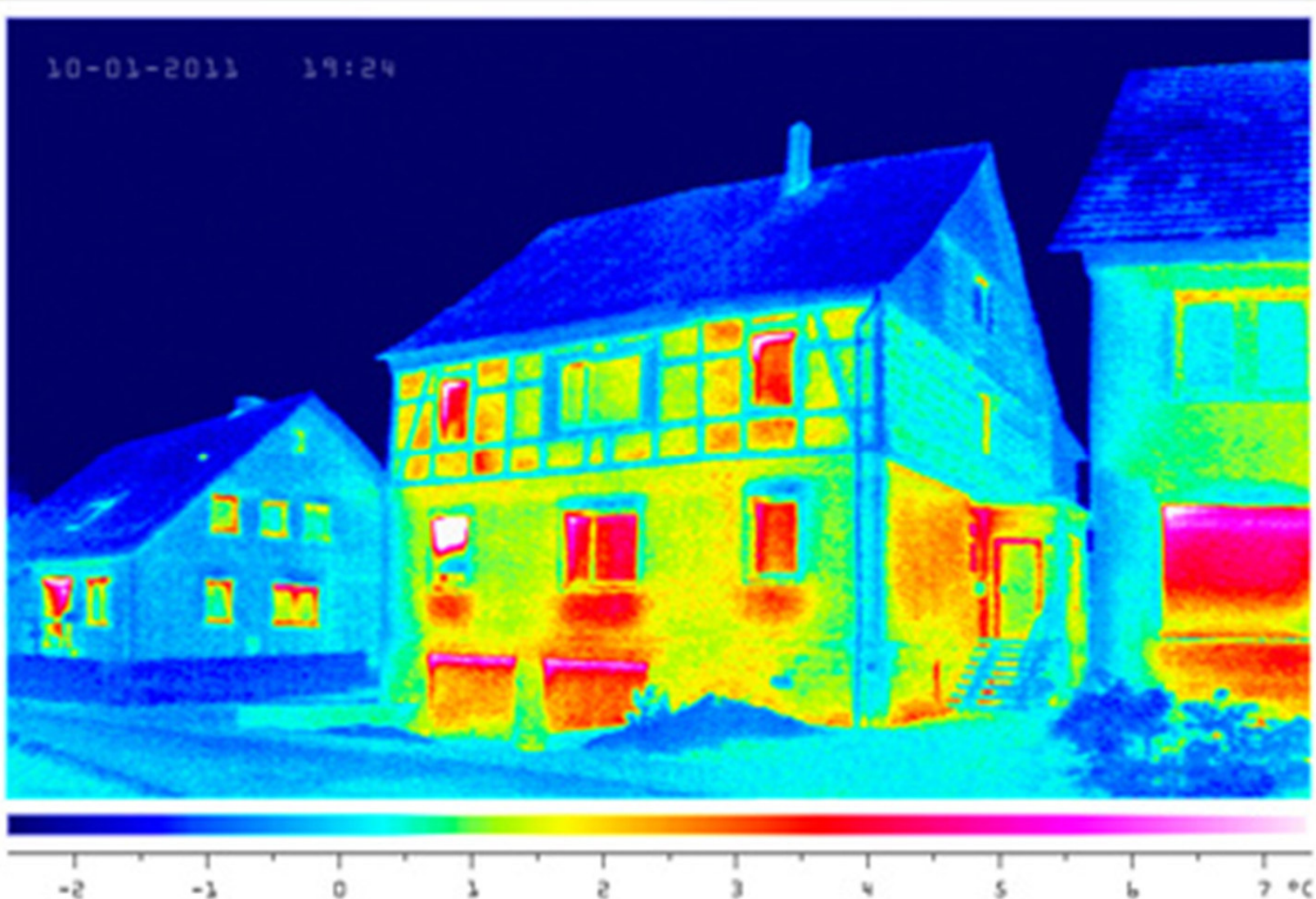

$-1$

o

b

3

5 


\title{
Energy autonomy in residential buildings: a techno-economic model-based analysis of the scale effects
}

\author{
Russell McKenna, Erik Merkel, Wolf Fichtner
}

Corresponding author: mckenna@kit.edu, +49 7216084 4582, IIP, Building
06.33, Hertzstr. 16, 76187 Karlsruhe, Germany.

An increasingly decentralized energy supply structure alongside economic incentives for increasing the level of self-generation and -consumption are encouraging (higher levels of) energy autonomy. Previous work in this area has focused on the technical and economic aspects of energy autonomy at distinct scales, from individual buildings, through neighbourhoods to districts. This paper employs a mixed integer linear program (MILP) to assess the effects of aggregation across these scales on the economics of energy autonomy in residential buildings. The model minimizes total energy system costs over the lifetime of the energy system, including micro-CHP, PV, thermal and electrical storage, and boilers, at five distinct scales and for nine demand cases. It is subject to several constraints, amongst other things the degree of electrical self-sufficiency. The results indicate a shift in the economically optimal level of electrical self-sufficiency with scale, which in Single Family Households (SFHs) means from around $30 \%$ at the individual building level to almost $100 \%$ in districts of $1000 \mathrm{SFH}$ households. Above around 560 households it could be economically advantageous to make a district of residential buildings electrically self-sufficient. In addition, a marginal increase in electrical self-sufficiency is significantly more expensive at lower aggregation scales (i.e. single buildings) compared to the scale of neighbourhoods and districts. The level of interaction with the electrical distribution network increases with increasing electrical self-sufficiency before then decreasing at very high (above $70 \%$ ) levels. Future work should focus on a richer socioeconomic differentiation, considering other sectors and technologies, incorporating demand side options and analysing the effects on the overarching energy system. 


\title{
Energy autonomy in residential buildings: a techno-economic model- based analysis of the scale effects
}

\author{
Russell McKenna ${ }^{1}$, Erik Merkel, Wolf Fichtner \\ Chair of Energy Economics, Karlsruhe Institute of Technology, Karlsruhe, Germany
}

\begin{abstract}
An increasingly decentralized energy supply structure alongside economic incentives for increasing the level of self-generation and -consumption are encouraging (higher levels of) energy autonomy. Previous work in this area has focused on the technical and economic aspects of energy autonomy at distinct scales, from individual buildings, through neighbourhoods to districts. This paper employs a mixed integer linear program (MILP) to assess the effects of aggregation across these scales on the economics of energy autonomy in residential buildings. The model minimizes total energy system costs over the lifetime of the energy system, including micro-CHP, PV, thermal and electrical storage, and boilers, at five distinct scales and for nine demand cases. It is subject to several constraints, amongst other things the degree of electrical self-sufficiency. The results indicate a shift in the economically optimal level of electrical self-sufficiency with scale, which in Single Family Households (SFHs) means from around $30 \%$ at the individual building level to almost $100 \%$ in districts of $1000 \mathrm{SFH}$ households. Above around 560 households it could be economically advantageous to make a district of residential buildings electrically self-sufficient. In addition, a marginal increase in electrical selfsufficiency is significantly more expensive at lower aggregation scales (i.e. single buildings) compared to the scale of neighbourhoods and districts. The level of interaction with the electrical distribution network increases with increasing electrical self-sufficiency before then decreasing at very high (above 70\%) levels. Future work should focus on a richer socioeconomic differentiation, considering other sectors and technologies, incorporating demand side options and analysing the effects on the overarching energy system.
\end{abstract}

\section{Introduction}

Buildings and urban areas have attracted much attention in the context of decarbonizing the energy system due to their large proportion of the global energy demand and the increasing proportion of the population living in them (IEA 2012). On the one hand there is a large potential for energy efficiency improvements on the demand side. This means the refurbishment of existing, and higher standards in new buildings, whereby the greatest challenge lies in the former area due to their sheer number (McKenna et al. 2013). On the other hand, renewable and highly efficient energy sources promises to meet the remaining demand with low or zero carbon energy supply.

Partly due to the low energy density and highly distributed nature of renewable energy sources, much of their utilization has been decentralized, e.g. photovoltaic (PV) on buildings, biomass and

\footnotetext{
${ }^{1}$ Corresponding author: mckenna@kit.edu, +49 7216084 4582, IIP, Building 06.33, Hertzstr. 16, 76187 Karlsruhe, Germany.
} 
wind plants within or near to municipalities. The majority of these plants in Germany are owned and operated by private individuals, including farmers and communities (Klaus Novy Institut e.V. \& trend:research 2011). Especially if located in or near a demand centre, an expansion of existing renewable energy capacity thus leads, ceteris paribus, to a higher level of local energy autonomy, which is generally defined here as that fraction of the local electricity demand met by local generation (see section 3 for precise definitions) ${ }^{2}$. The distinction is thereby made between net energy autonomy, i.e. balanced over the year, and complete energy autonomy, which implies an offgrid operation.

Some of the motivations for community energy projects that tend to increase the level of energy autonomy include greater independence from centralized energy markets (and their price fluctuations), relief of and/or independence from ${ }^{3}$ the local electrical transport and distribution networks (and thus lower network fees for the community), more control over local decisions relating to the energy system and a locally-sourced, low carbon energy supply (Müller at al. 2011, Rae \& Bradley 2012, Walker 2008).

Generally the adoption of renewable energies has relied on political support in the form of quota systems and feed-in tariffs, although others such as investment grants and tax exemptions do exist. For PV this was until quite recently the case, but now this technology has reached grid parity in several countries (Briano et al. 2015). This means that the generation costs, expressed as the levelized costs of electricity generation (LCOE), are at or below the electricity price for the end consumer. The discrepancy between electricity generation and residential demand profiles, however, makes increasing the fraction of self-consumed electricity in the absence of an electrical storage system quite challenging. Hence there has been renewed interest in battery storage devices for small-scale, decentralized domestic applications.

Some key research questions arise from this current situation, in which there are motivations for increasing energy autonomy at the individual building, neighbourhood and district scales. One question relates to the economically optimum scale at which energy autonomy should be strived for, if at all. A second question relates to the economically optimum technology combination and dispatch at different spatial scales, given the resource constraints and costs in a given local energy system. A third question relates to the implications for the local distribution network of various levels of energy autonomy and scales. The present contribution addresses these questions by developing and applying a mixed integer linear programming (MILP) model for decentralized generation technologies in a residential building context. The model is applied to several demand cases, from the individual building up to the neighbourhood and district scales. The paper is structured as follows. The following section provides an overview of the relevant literature on this subject, from which the specific objectives of the current study and the research gaps it aims to fill are derived. Section 3 described the methodology, section 4 presents the results, and section 5 includes a discussion of these results as well as a sensitivity study and a critique of the methodology. The paper closes with a summary and conclusions (section 6).

\footnotetext{
${ }^{2}$ Energy autonomy is used in this paper to refer to the general practice of local energy generation and use. Selfsufficiency and related terms are employed to measure the degree of energy autonomy with respect to electricity (see section 3 for details).

${ }^{3}$ It should be noted here that German has one of the highest levels of electricity system security of supply, as measured by the SAIDI, System Average Interruption Duration Index, indicator, in Europe. On average over the past years the SAIDI was at around 16 minutes per year for end-consumers (BMWi 2014).
} 


\section{Literature review}

Much research has analyzed the different options for exploiting decentralized and efficient energy system potentials locally. Thereby the focus often lies on the economic, technical and/or environmental assessment of the available resources, technologies and measures. Thus decision support can be developed in the form of strategies, which can help to aid decision making relating to the implementation of specific or a whole selection of measures. In this context it is useful to distinguish between three approximately distinct scales, namely individual buildings, neighbourhoods and districts, as discussed in the following subsections.

\subsection{Individual buildings}

Even if diverse decentralized energy technologies are exploited, it is unlikely that high levels of energetic autonomy can be achieved at the building scale without some kind of storage device. One technological option is to convert electricity into hydrogen through electrolysis and then store the hydrogen to be later used for cogeneration of heat and power in a fuel cell. Marino et al. (2013) carried out an environmental, economic and energy analysis of such a system in three specific configurations, namely in combination with a wind turbine, a PV module, and both, for a public building. In both cases the renewable plants are dimensioned in order to enable an off-grid operation, which means at times of low renewable generation and high demand, this whole demand should be met from the hydrogen storage and fuel cell. The overall low efficiency of $25 \%$ for conversion from electricity to hydrogen means that the conceptually stand-alone system is only economical when connected to the grid and thus benefitting from current feed-in tariffs for renewable electricity, with a dynamic payback period of around 15 years in this case. This study does not analyse battery storage options.

Comodi et al. (2015) analyse a multi-apartment residential microgrid by comparing different energy management approaches in terms of overall costs. The microgrid consists of six apartments, a $20 \mathrm{~kW}_{\mathrm{p}}$ photovoltaic plant, a solar based thermal energy plant, a geothermal heat pump, a thermal energy storage and two $5.8 \mathrm{kWh}$ batteries. The authors conclude that the utilization of battery storage units can help to achieve a self-consumption rate (cf. section 3 ) of about $60 \%$, with fully autonomous (offgrid) operation for around 3100-3300 hours per year, but high battery costs are currently a limiting factor in terms of their profitability, especially when compared with thermal storage. This study does not consider mCHP technologies, however.

Also, Milan et al. (2012) have developed and applied a cost-optimization model for $100 \%$ renewable energy supply, including PV, heat pump and solar thermal plant with a thermal storage, and applied it to a residential near-Zero Energy Building (nZEB) in Denmark. The approach considers the embodied energy in the energy supply units, but not in the building fabric or deconstruction thereof. The results show that a large PV capacity of $10 \mathrm{~kW}_{\mathrm{p}}$ is required to meet annual demand, including that of the heat pump. No solar thermal plant is installed, but it might be if the heat supply options were operated in series rather than in parallel as in this case, and $37 \%$ of the electricity demand is directly met by the PV unit as no electric storage is employed. As in the case of Marino et al. (2013), the systems are somewhat over-dimensioned in order to ensure security of supply even on the 
coldest days of the year, and Milan et al. (2012) do not investigate the application of a mCHP and/or battery to such a building.

Another strand of relevant research at the building level is concerned with the optimum sizing and orientation of PV systems, including battery storage, for individual buildings (Weniger et al. 2013, Widen et al. 2009, Mondol et al. 2009). Weniger et al. (2013) optimize the sizing of residential PV and battery systems with a view to maximizing the self-consumption rate and degree of self-sufficiency. Widen et al. (2009) focus on the technical potential for matching the electricity generation from PV with the load profile, by considering different sizing, orientation, DSM (demand side management) and electricity storage combinations. The main findings are that storage is the most attractive option at higher renewable penetration levels, whereas DSM is as effective or even superior at lower penetrations. Mondol et al. (2009) consider economic aspects of PV electricity generation and thus investigate the scope for matching the generation profile of the PV system to the load by accounting for the impact of array size, orientation, inclination, PV/inverter sizing ratio and PV/inverter cost ratio on the economics. Based on location-specific electricity load profiles, irradiation and feed in tariffs as well as electricity prices, the model is applied to several European locations. The results demonstrate the sensitivity of PV-electricity generation costs to the setup of the system (especially the ratio of the PV module to the inverter) as well as suggesting that feed-in of this electricity should be avoided when the tariff lies below the electricity price. One limitation of the economic assessment is that it is based on feed-in tariffs and electricity prices which are assumed to be constant.

\subsection{Neighbourhoods}

Several authors have examined the multi-energy supply of several buildings in a neighbourhood context (Orehouning et al. 2015, De Conick et al. 2013, Baetens et al. 2012). For example, Orehouning et al. (2015) model an energy hub with distributed and centralized energy generators. The approach involves optimizing the dispatch of a multi-vector energy system including production, storage and demand systems (the energy hub). The authors investigate 29 buildings, with 4 building types and 4 different configurations consisting of various centralized and decentralized renewables. The objective function is to minimize the environmental impact, in terms of lifecycle $\mathrm{CO}_{2}$ emissions. The results suggest an energy autonomy of the neighbourhood limited to $86 \%$ without storage, with ranges between $64-92 \%$, and best results in terms of energy autonomy integrate a diversity of energy sources. Comparison of the local generation options with imports from the grid demonstrates specific savings of $\mathrm{CO}_{2}$, energy and energy autonomy.

De Conick et al. (2013) and Baetens et al. (2012) apply similar approaches to the modelling of small neighbourhoods consisting of 33 households of four types, each of which is made a Zero Energy Building (ZEB) through adequate sizing of heat pumps and PV systems, for which they employ the IEEE model distribution network typology. The focus in Baetens et al. (2012) is on the effects on the local distribution network of having a significant number of ZEBs in one neighbourhood, hence local shared electric or heat storage units are not considered. Amongst other things the authors conclude that, when feeder restrictions are not considered, the main advantage in aggregating several buildings lies in the smaller (specific, per building) dimensioning of PV capacities. The main limitations of these two studies lie in the focus on identical buildings, which are configured as nZEBs, and the neglecting of electrical storage units and scale effects. 


\subsection{Districts}

Finally, some authors have analyzed the scope to increase the self-sufficiency of a renewable-energydominated system at the district scale (Killinger et al. 2014, Schmidt et al. 2012, Jenssen et al. 2010, Burgess et al. 2012). Killinger et al. (2014) investigate the scope for selected German municipalities to become electrically autonomous on a net annual basis by exploiting local wind and PV resources. They examine four regions, chosen for their diversity in terms of renewable energy resources and demand structure and size. The energy supply is optimized with respect to three energy political criteria, namely economic efficiency, security of supply, and environmental sustainability, operationalized as of costs of energy supply, degree of energy autonomy and $\mathrm{CO}_{2}$ intensity of electricity supply, respectively. The authors find that there is substantial scope to achieve these different goals through different combinations of wind and PV capacities, as well as diverse orientations of PV systems, but that the goals partly compete with one another.

Schmidt et al. (2012), Jenssen et al. (2010) and Burgess et al. (2012) all analyze the scope for achieving energy autonomy for small, mainly rural districts with biomass, PV and wind resources. Schmidt et al. (2012) examine the agriculturally dominated rural region of Sauwald in Upper Austria, with 21,000 inhabitants, concluding that, whilst the biomass can replace fossil fuels for heating at relatively low cost, attaining a full energy-autonomous heat and electricity supply would require an exploitation of all biomass resources and an installation of PV panels on all rooftops. Hence in this particular case energy autonomy implies higher costs for consumers as well as a reduction in the overall local production of food. This is a conclusion that Jenssen et al. (2010) confirm, in their overview of experiences and lessons learned so far in the so called "bioenergy villages" in Germany. They contrast the advantage of reduced local $\mathrm{CO}_{2}$ emission with the disadvantages of increased costs and competing land use (e.g. for food). A $100 \%$ (net, annual) energy autonomy from biomass is technically possible within the model municipality studied, but less reasonable and favourable with respect to land use competition and higher costs of energy supply. Finally, Burgess et al. (2012) present a case study of an Marsten Vale (16000 ha) in southern England, UK, interestingly considering food and material use next to energy, and therefore the land use competition relating to these uses. The main conclusion is that, whilst large fractions of the demand for electricity can be met by the available resources, there are limits to meeting the demands for heating and transport. The authors therefore highlight the need to reduce demand through energy efficiency and similar measures if regions are to become fully autonomous.

\section{4. $\quad$ Synthesis and objectives}

The foregoing discussion has highlighted the motivation and presented some previous attempts to quantitatively analyze the technical and economic feasibility of energy autonomy from the building through the neighbourhood to the district scale. It is clear from this discussion that (net) energy autonomy is technically possible at many of these scales. In addition, if these approaches are based predominantly or wholly on renewable energy resources, a strong exchange with the local distribution network and/or large thermal and electrical storage technologies are required. The aggregation of energy systems through these scales smooths the aggregate load profiles and enables communal storage infrastructure to be dimensioned relatively smaller (i.e. per household) than in the case of individual buildings. But it remains unclear if there is an optimum scale for a partly or 
wholly energy-autonomous system. The current contribution therefore analyzes the effects of scale on attempts to achieve energy autonomy within an urban context. Rather than to analyse completely autonomous energy systems, the focus lies on the tendency towards higher levels of autonomy for the electricity and heat supply in existing residential buildings.

A cost-optimisation model is developed and applied to nine residential building demand cases at five different scales, in order to achieve progressive levels of energy autonomy. The energy supply systems consist of $\mathrm{mCHP}, \mathrm{PV}$, gas boilers and thermal and electrical energy storage devices, and buildings are differentiated in terms of their size and number of occupants. The following section describes the developed model and the derivation of the demand cases.

\section{Methodology}

\subsection{Existing CHP model and main extensions}

The applied optimisation model focuses on deriving the optimal capacity and dispatch for decentralised electricity and heat supply systems under the premise of least total cost of energy supply in the residential context. The existing model investigates energy supply systems consisting of a micro-CHP unit, a gas boiler and a thermal storage unit. It has been applied to a number of different building objects and is described in detail in Merkel et al. (2015).

For this contribution the model is further developed and extended by a number of model components. The energy supply and storage options considered in Merkel et al. (2015) are complemented by a photovoltaic system (PV) and a battery storage. In addition, electricity can be sourced from the electricity grid which is model-endogenous but neither represents a technology nor an investment decision. Likewise, the building objects which constitute the consumption side in the energy system under investigation are integrated into the model using their total annual levels of electricity and heat consumption as well as their load profiles. Table 1 gives an overview of the technologies that can be chosen in the optimisation and Figure 1 gives an overview of the methodology of the optimisation model for the analysis of energy autonomy.

\begin{tabular}{|l|c|c|c|c|c|}
\hline & Gas boiler & Micro-CHP & PV & Thermal storage & Battery storage \\
\hline Capacity unit & $\mathrm{kW}_{\mathrm{th}}$ & $\mathrm{kW}_{\mathrm{el}}$ & $\mathrm{kW}_{\mathrm{el}}$ & $\mathrm{l}$ & $\mathrm{kWh}_{\mathrm{el}}$ \\
\hline
\end{tabular}

Table 1: Overview of the eligible technologies in the optimisation approach

The degree of self-sufficiency is either given model-exogenously as a fixed level and thus serves as model input or it is left free to the optimisation. Furthermore, the degree of self-sufficiency and rate of self-consumption relating to electricity are reported in case they is not stipulated ex-ante as a fixed level for the model runs.

The model horizon is 20 years with the base year being 2015. The temporal resolution amounts to 15 minutes. The year is not modelled in full chronological order based on 52 weeks but partitioned into 
representative segments meaning that 3 non-consecutive weeks from the summer, winter and spring/autumn season constitute the time base in the model respectively. This amounts to 9 weeks considered in the model which are extended to the full year scale applying a weighting factor.

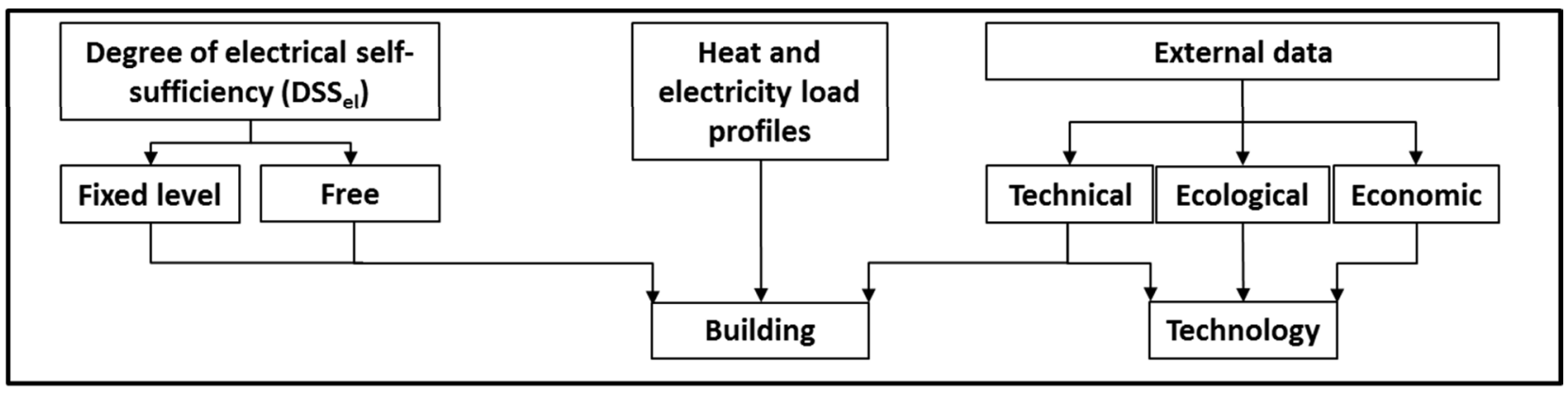

Data processing

Optimisation model of the capacity and dispatch (MILP)

Output

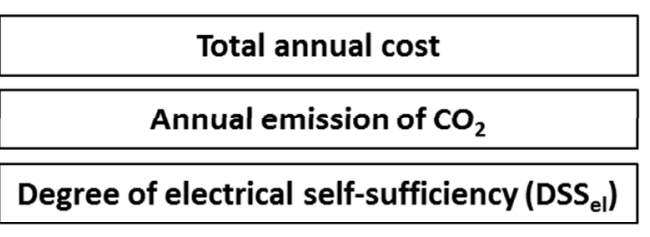

Capacity

Dispatch

Rate of self-consumption $\left(\mathrm{SCR}_{\mathrm{el}}\right)$

Figure 1: Overview of the methodology of the optimisation model for the analysis of energy autonomy

\subsection{Modelling of PV and battery storage}

The objective function $f$ of the optimisation model is defined according to equation 3-1. Therein, the total system cost summed over every energy supply unit over the planning horizon is incurred.

$$
\min f=\sum_{p=1}^{P}\left(c_{i n v, p}+c_{f i x, p}+\propto \cdot \sum_{t=1}^{T}\left(c_{v a r, p, t}-c_{r e v, p, t}\right)\right)
$$

where

$c_{i n v, p} \ldots$ Capital-related annual cost of energy supply unit $\mathrm{p}$

$c_{f i x, p} \ldots$ Fixed annual cost of energy supply unit $\mathrm{p}$

$c_{v a r, p, t} \ldots$ Variable operation cost of $\mathrm{p}$ in time step $\mathrm{t}$

$c_{r e v, p, t} \ldots$ Revenue from $\mathrm{p}$ in time step $\mathrm{t}$ 
$\propto$... Weighting factor for aggregation to a full calendrical year

In the objective function the capital-related cost for the additionally considered technologies PV and battery storage are derived by an approach of piecewise-linear approximation of the concave function of investment as outlined in Merkel et al. (2015). Thereby, economies of scale are also taken into account for the PV and battery storage. Furthermore, the revenues generated from the electricity generation of the energy supply units has to be adapted to the inclusion of PV in the model. Thus equation 3-2 describes the revenues induced by the CHP and PV unit. It should be noted that in addition to the equation defined in Merkel et al. (2015) a levy on the generation of electricity for self-consumption is introduced. This is in line with the relevant specifications of remuneration policy as defined for example in the Renewable Energy Sources Act in Germany.

$$
c_{r e v, p, t}=x_{e l, e}^{p}(t) \cdot c_{r e v, e}^{p}+x_{e l, i}^{p}(t) \cdot\left(c_{r e v, i}^{p}-c_{l e v y}^{p}\right) \forall p \in\{C H P, P V\} ; t \in T
$$

where

$x_{e l, e}^{p}(t) \ldots$ Electricity output of $\mathrm{p}$ for external use (fed-back to electricity grid) in time step $\mathrm{t}$

$x_{e l, i}^{p}(t) \ldots$ Electricity output of $\mathrm{p}$ for internal use (self-consumption) in time step $\mathrm{t}$

$c_{\text {rev,e }}^{p} \ldots$ Revenue for electricity exported from $\mathrm{p}$

$c_{r e v, i}^{p} \ldots$ Revenue for electricity generated from $\mathrm{p}$

$c_{\text {levy }}^{p} \ldots$ Levy for electricity generated from $\mathrm{p}$

As for the modified or additional constraints of the extended optimisation model, the following equations are highlighted. The fulfilment of the demand for electricity is formulated in equation 3-3. The demand can be met by either the generation of the electricity-producing units, i.e. a CHP and a PV plant, the battery storage or by the sourcing from the electricity grid.

$$
x_{e l, i}^{C H P}(t)+x_{e l, i}^{P V}(t)+\left(1-\varrho^{B S}\right) \cdot x_{e l, o u t}^{B S}(t)+x_{e l}^{g r i d}(t) \geq \operatorname{dem}_{e l}(t) \quad \forall t \in T
$$

where

$x_{e l, i}^{C H P}(t) \ldots$ Electricity output of the CHP unit for internal use (self-consumption) in time step $\mathrm{t}$

$x_{e l, i}^{P V}(t) \ldots$ Electricity output of the PV unit for internal use (self-consumption) in time step $\mathrm{t}$

$x_{\text {el,out }}^{B S}(t)$... Electricity output of the battery storage in time step $t$

$x_{e l}^{g r i d}(t) \ldots$ Electricity input from the grid in time step $\mathrm{t}$

$\varrho^{B S} \ldots$ Battery storage loss 
The balance equations for the battery storage are described in the equations 3-4 and 3-5. The storage level of the successive time step equals the one of the preceding time step augmented by the storage inflow and reduced by the storage outflow.

$$
x_{e l, l}^{B S}(t)=x_{e l, l}^{B S}(t-1)+x_{e l, i n}^{B S}(t)-x_{e l, o u t}^{B S}(t) \quad \forall t \in T
$$

where

$x_{e l, l}^{B S}(t) \ldots$ Level of the battery storage in time step $\mathrm{t}$

$x_{e l, i n}^{B S}(t) \ldots$ Electricity input of the battery storage in time step $\mathrm{t}$

The inflow of the battery storage is therefore comprised of the electricity output of the CHP and the $\mathrm{PV}$ unit for internal use as can be seen from equation 3-5.

$$
x_{e l, i n}^{B S}(t)=\left(1-\varrho^{B S}\right) \cdot\left(x_{e l, i}^{C H P}(t)+x_{e l, i}^{P V}(t)\right) \forall t \in T
$$

Moreover, the level of the battery storage is capped by its maximum capacity at every point in time. This is indicated in equation 3-6.

$$
x_{e l, l}^{B S}(t) \leq x_{c a p}^{B S} \forall t \in T
$$

where

$x_{\text {cap }}^{B S} \quad$... Capacity of the battery storage

Additionally, the electricity output of the battery storage is related to the storage capacity by a fixed factor indicating the charge rate (c-rate) of the battery. Therefore, this relationship is established in equation 3-7.

$$
x_{\text {el,out }}^{B S}(t) \leq x_{\text {cap }}^{B S} \cdot c^{B S} \cdot \beta \quad \forall t \in T
$$

where

$c^{B S} \ldots$ Charge rate of the battery storage

$\beta$... Hour fraction 
Finally, the electricity generation of the PV unit is dependent on the solar irradiation that is absorbed by the panels. Thus the generation has to be related to the irradiation profile which is ensured by equation 3-8.

$$
x_{e l, i}^{P V}(t)+x_{e l, e}^{P V}(t) \leq x_{c a p}^{P V} \cdot \eta_{t o t}^{P V} \cdot a^{P V}(t) \quad \forall t \in T
$$

where

$x_{e l, e}^{P V}(t) \ldots$ Electricity output of the PV unit for external use (fed-back to electricity grid) in time step t

$x_{\text {cap }}^{P V} \ldots$ Installed capacity of the PV unit

$\eta_{t o t}^{P V} \ldots$ Total electric efficiency of the PV unit

$a^{P V}(t) \ldots$ Normalised solar irradiation in time step $\mathrm{t}$

For a more detailed mathematical description of the presented optimisation model, e.g. with regard to the operation characteristics of the CHP unit, the reader is referred to Merkel et al. (2015).

\subsection{Additional constraints for energy autonomy}

In addition, for the determination of the energy autonomy, additional constraints have to be defined. These relate to the degree of self-sufficiency and the rate of self-consumption relating to electricity. Therefore equation 3-9 establishes the degree of self-sufficiency with respect to electricity.

$$
D S S_{e l}=\frac{\sum_{t=1}^{T}\left(x_{e l, i}^{C H P}(t)+x_{e l, i}^{P V}(t)\right)}{\sum_{t=1}^{T} \operatorname{dem}_{e l}(t)}
$$

In equation 3-9 the total electricity generation deemed for internal use, i.e. self-consumption on-site by the CHP and PV units, is related to the total electricity demand within the period under investigation. Equation 3-10 defines the rate of self-consumption referring to electricity in the present context.

$$
S C R_{e l}=\frac{\sum_{t=1}^{T}\left(x_{e l, i}^{C H P}(t)+x_{e l, i}^{P V}(t)\right)}{\sum_{t=1}^{T}\left(x_{e l, i}^{C H P}(t)+x_{e l, e}^{C H P}(t)+x_{e l, i}^{P V}(t)+x_{e l, e}^{P V}(t)\right)}
$$

Thus the electricity generation of the CHP and PV plant that is deemed for self-consumption is divided by the total electricity generation of the units. Finally, the degree of electrical autonomy $D A_{e l}$ is defined as the ratio of $\mathrm{DSS}_{\mathrm{el}}$ and $\mathrm{SCR}_{\mathrm{el}}$ according to equation 3-11. 


$$
D A_{e l}=\frac{D S S_{e l}}{S C R_{e l}}=\frac{\sum_{t=1}^{T}\left(x_{e l, i}^{C H P}(t)+x_{e l, e}^{C H P}(t)+x_{e l, i}^{P V}(t)+x_{e l, e}^{P V}(t)\right)}{\sum_{t=1}^{T} \operatorname{dem}_{e l}(t)}
$$

In addition, the Grid Interaction Index (GII) is a measure of the degree of variability in the net electricity export to the grid and is defined according to equation 3-12 (Salom et al. 2011). The GII normalized with the GII of the input load profiles $\left(G \|_{\text {norm }}\right)$ is then defined as given in equation 3-13. $E(i)$ is the net electricity export to the grid in timeslot $i$.

$$
\begin{aligned}
& G I I=\operatorname{std}\left(\frac{E(i)}{\max (|E(i)|)}\right) \\
& G I I_{\text {norm }}=\frac{\mathrm{GII}}{G I I_{\text {ref }}}
\end{aligned}
$$

\subsection{Techno-economic assumptions}

The parameter assumptions which relate to the above equations and that the optimization runs are based on are shown in Table 2. The gas and electricity price developments (increases) are assumed to be $2 \%$ and $2.5 \%$ per year throughout the model horizon respectively. The solar irradiation is taken

\begin{tabular}{|c|c|c|}
\hline Parameter & Unit & Value \\
\hline$\propto$ & - & $52 / 9=5.77$ \\
\hline$\beta$ & - & $1 / 4=0.25$ \\
\hline$c_{\text {ele }}$ & $€ / \mathrm{kWh}_{\mathrm{el}}$ & 0.29 \\
\hline $\mathrm{c}_{\text {gas }}$ & $€ / \mathrm{kWh}$ & 0.07 \\
\hline$c_{\text {fix }, \text { BOI }}$ & $€ /\left(\mathrm{kW}_{\text {th }} \mathrm{a}\right)$ & 10 \\
\hline $\mathrm{c}_{\mathrm{fix}, \mathrm{CHP}}$ & $€ /\left(\mathrm{kW}_{\mathrm{el}} \mathrm{a}\right)$ & 150 \\
\hline $\mathbf{c}_{\mathrm{fix}, \mathrm{PV}}$ & $€ /\left(\mathrm{kW}_{\mathrm{el}} \mathrm{a}\right)$ & 100 \\
\hline $\mathrm{c}^{\mathrm{BS}}$ & - & 1 \\
\hline$c_{\text {levy }}^{P V}$ & $€ / \mathrm{kWh}_{\mathrm{el}}$ & 0.019 \\
\hline$c_{\text {rev,i }}^{\mathrm{CHP}}$ & $€ / \mathrm{kWh}_{\mathrm{el}}$ & 0.0541 \\
\hline $\mathbf{c}_{\mathrm{rev}, \mathrm{i}}^{\mathrm{PV}}$ & $€ / \mathrm{kWh}_{\mathrm{el}}$ & 0.10 \\
\hline$c_{\text {rev,e }}^{\text {CHP }}$ & $€ / \mathrm{kWh}_{\mathrm{el}}$ & 0.10 \\
\hline $\mathbf{c}_{\mathrm{rev}, \mathrm{e}}^{\mathrm{PV}}$ & $€ / \mathrm{kWh}_{\mathrm{el}}$ & 0.10 \\
\hline$\eta_{\mathrm{tot}}^{\mathrm{PV}}$ & $\%$ & 85 \\
\hline$\varrho^{B S}$ & - & 0,05 \\
\hline $\mathbf{T}$ & $\mathrm{a}$ & 20 \\
\hline
\end{tabular}
from Rehmund et al. (2014) and specific investments for PV and battery systems are derived from manufacturers data and EuPD Research (2014).

Table 2: Overview of the parameter assumptions for the optimization runs 


\subsection{Definition of dwelling and building cases}

In total, nine different configurations are considered in this study, which are combinations out of buildings and households. The nine cases consist of a building type, single family house (SFH) and multi-family house (MFH) respectively, and number of occupants, defined according to national statistics (Statistisches Bundesamt 2013). This source includes data on the average number of people per type of building, i.e. SFH and MFH, as well as the number of apartments per block.

The considered buildings are assumed to be typical of the German residential building stock. Hence their annual heat demands are taken from the VDI Guideline 4655 (VDI, 2008), which is a standard for determining residential heat demands. Thereby the size of the buildings are also taken from the national statistics and therefore represent averages (Statistisches Bundesamt 2008). The load profiles for the demand cases shown above are generated with two existing models. The electrical load profiles are produced with the open-source tool developed by the CREST group at Loughborough University and documented by Richardson et al. (2010). This model produces stochastic daily load profiles for dwellings configured in terms of the number of occupants, the day of the week and the season. The model is run as many times as unique load profiles are required (i.e. the number of household units, cf. Table 3). The final input for the optimization model are the heat load profiles for domestic hot water and space heating, which are obtained from a detailed TRNSYS simulation model of German buildings (Klein et al, 2010). An overview of these demand cases is given in Table 3 below.

\begin{tabular}{|c|c|c|c|c|c|c|c|c|c|}
\hline \multirow{2}{*}{$\begin{array}{c}\text { Aggregation } \\
\text { level }\end{array}$} & \multirow[t]{2}{*}{ Case } & \multirow{2}{*}{$\begin{array}{l}\text { No. of } \\
\text { housing } \\
\text { units }\end{array}$} & \multicolumn{5}{|c|}{ Probability of this no. of residents } & \multirow{2}{*}{$\begin{array}{l}\text { Annual } \\
\text { heat } \\
\text { demand } \\
\text { for SH } \\
\text { and DHW } \\
\text { (MWh/a) }\end{array}$} & \multirow{2}{*}{$\begin{array}{l}\text { Annual } \\
\text { electricity } \\
\text { demand } \\
\text { (kWh/a) }\end{array}$} \\
\hline & & & 1 & 2 & 3 & 4 & 5 & & \\
\hline Single SFH & SFH_1a & 1 & 0.0 & 1.0 & 0.0 & 0.0 & 0.0 & 31 & 3252 \\
\hline Single SFH & SFH_1b & 1 & 0.0 & 0.0 & 0.0 & 1.0 & 0.0 & 31 & 6504 \\
\hline Street of SFHs & SFH_13 & 13 & 0.5 & 0.3 & 0.1 & 0.1 & 0.0 & 98 & 47052 \\
\hline Single MFH & MFH_13 & 13 & 0.2 & 0.4 & 0.2 & 0.2 & 0.1 & 80 & 46319 \\
\hline SFH block & SFH_100 & 100 & 0.5 & 0.3 & 0.1 & 0.1 & 0.0 & 3050 & 438707 \\
\hline MFH block & MFH_100 & 100 & 0.2 & 0.4 & 0.2 & 0.2 & 0.1 & 1952 & 382661 \\
\hline Neighbourhood & SFH_192 & 192 & 0.5 & 0.3 & 0.1 & 0.1 & 0.0 & 6230 & 712327 \\
\hline City district & SFH_1000a & 1000 & 0.5 & 0.3 & 0.1 & 0.1 & 0.0 & 43201 & 4474495 \\
\hline City district & SFH_1000b & 1000 & 0.5 & 0.3 & 0.1 & 0.1 & 0.0 & 43201 & 4474495 \\
\hline
\end{tabular}

Table 3: Overview of demand case definitions used in this study 


\section{Results}

\subsection{Energy supply costs}

In Figure 2 the total annual costs of energy supply per household are outlined. The cost refers to the provision of energy services, including the electricity, space heating and hot water demands. Furthermore, in the graph the total costs are differentiated by the given degree of electrical selfsufficiency for every demand case considered, leading to 11 levels ranging from $0 \%$ to $100 \%$. In addition, the total cost resulting from the optimization runs not restricted to any level of selfsufficiency, referred to as the "free case", is shown. For the latter, the corresponding ex-post determined degree of electrical self-sufficiency is further quantified. The left side of the graph refers to the single-family houses in ascending order of number of households according to the case definition in Table 3. Additionally, for comparison the two investigated multi-family houses which relate to the cases SFH_13 and SFH_100 in terms of the number of households are depicted in the right hand side of the chart.

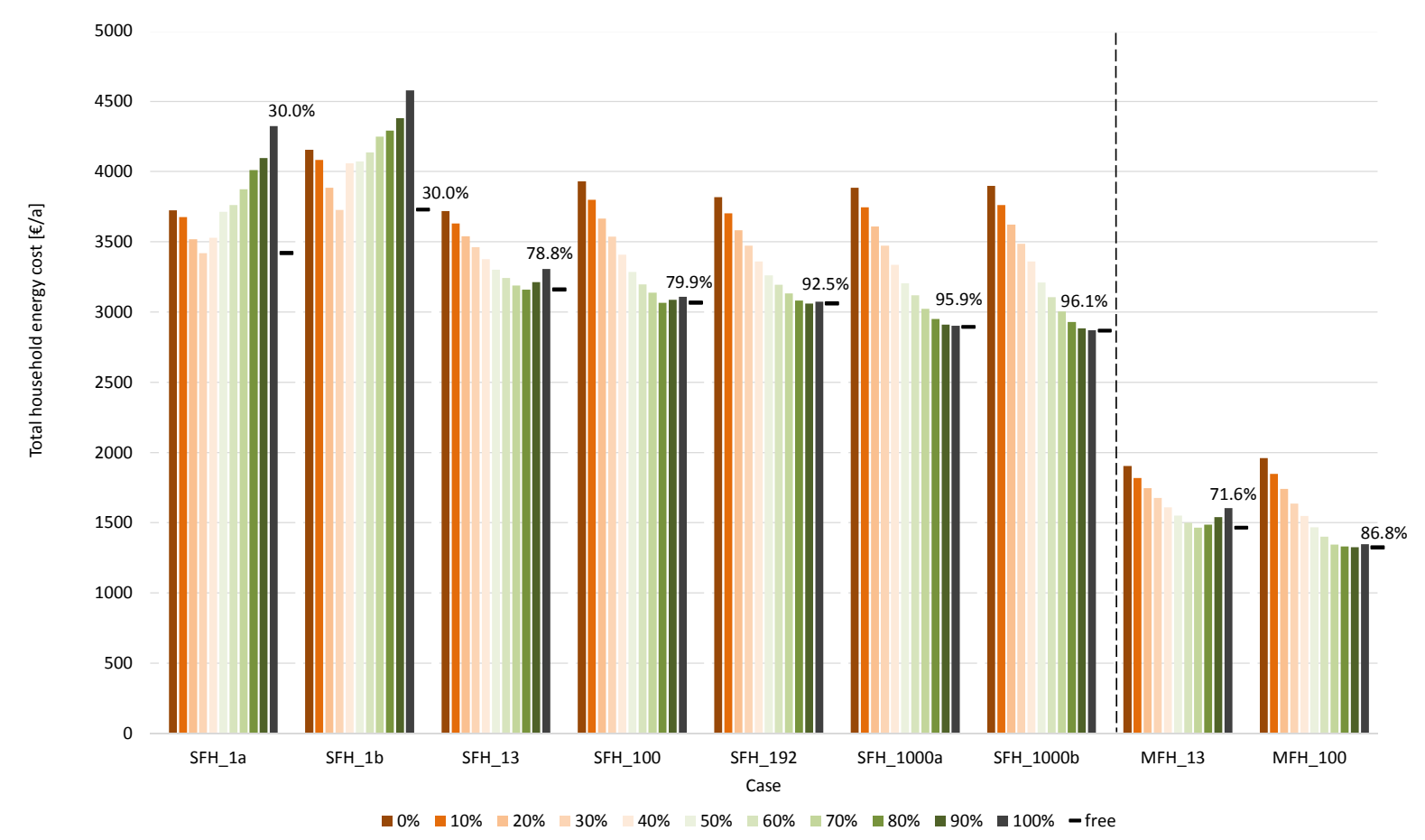

Figure 2: Total annual cost of energy supply per household for the investigated buildings at a given level of electrical self-sufficiency (DSS ) and for the free optimization

From Figure 2 several observations can be made. Firstly, the total annual cost per household determined as the least costly option among the results for the given levels of electrical selfsufficiency decreases with an increasing number of households within the building cases. In more concrete terms, in a single-family house a total annual cost of $3,419 €$ and $3,728 €$ is incurred for case 
SFH_1a and SFH_1b respectively, whereas this figure reduces to $2,870 €$ in the case of 1,000 households (case SFH_1000b).

The large difference between the annual energy costs for SFH and MFH is lower annual heat consumption for the latter, resulting from a combination of lower specific living areas and specific heating demand on average (cf. section 3 ).

Another observation relates to the degree of self-sufficiency which is illustrated in Figure 2 both for the given levels and as a result of the free optimisation. The optimal degree of electrical selfsufficiency corresponding to the least-cost solution therefore increases with an increasing number of households in a monotone way. Graphically, the distribution of the total annual cost as a function of the degree of electrical self-sufficiency for the respective case is skewed to the right for the demand cases of a smaller number of households whereas it is skewed to the left for a higher number thereof. Thus, for single-family houses the optimal degree varies from 30.0\% (SFH_1a and SFH_1b) to 96.1\% (SFH_1000b).

\subsection{Installed capacities and technologies}

In Figure 3 below the installed capacities per household for the nine demand cases and five technologies are shown. This is total determined capacity for the cases divided by the number of households. Electric and thermal generation capacities are given in $\mathrm{kW}$ or kWh respectively on the left axis, whereas the thermal storage volume in liters is given on the right hand axis. The following general observations about this figure can be made:

- There are negligible, if any, capacities of the low carbon technologies considered here (PV, $\mathrm{mCHP}$, batteries) in the case of $0 \%$ self-sufficiency (not shown in the figure).

- With the exception of cases SFH_1000a and SFH_1000b (with $0.1 \mathrm{kWel}$ with 0\% electrical self-sufficiency respectively), CHP technologies are only installed at and above $20 \%$ electrical self-sufficiency rates. Above $60 \%$ electrical self-sufficiency rates their capacity per household increases only moderately.

- PV systems are only installed at and above $40 \%$ levels of electrical self-sufficiency, whereby all cases have PV systems at and above $60 \%$ electrical self-sufficiency.

- Batteries are only significantly used for levels of electrical self-sufficiency at and above $80 \%$, with the exception of cases SFH_1a and SFH_1b with 60\%.

- In general the specific capacity of the boiler is reduced for larger demand objects, and for multi-family-houses the specific capacity is significantly smaller due to the lower overall heat demand (compared to SFHs).

- The specific size of the thermal storage unit seems to peak for case SFH_192, but is significantly smaller than this for cases SFH_1000a and SFH_1000b. 


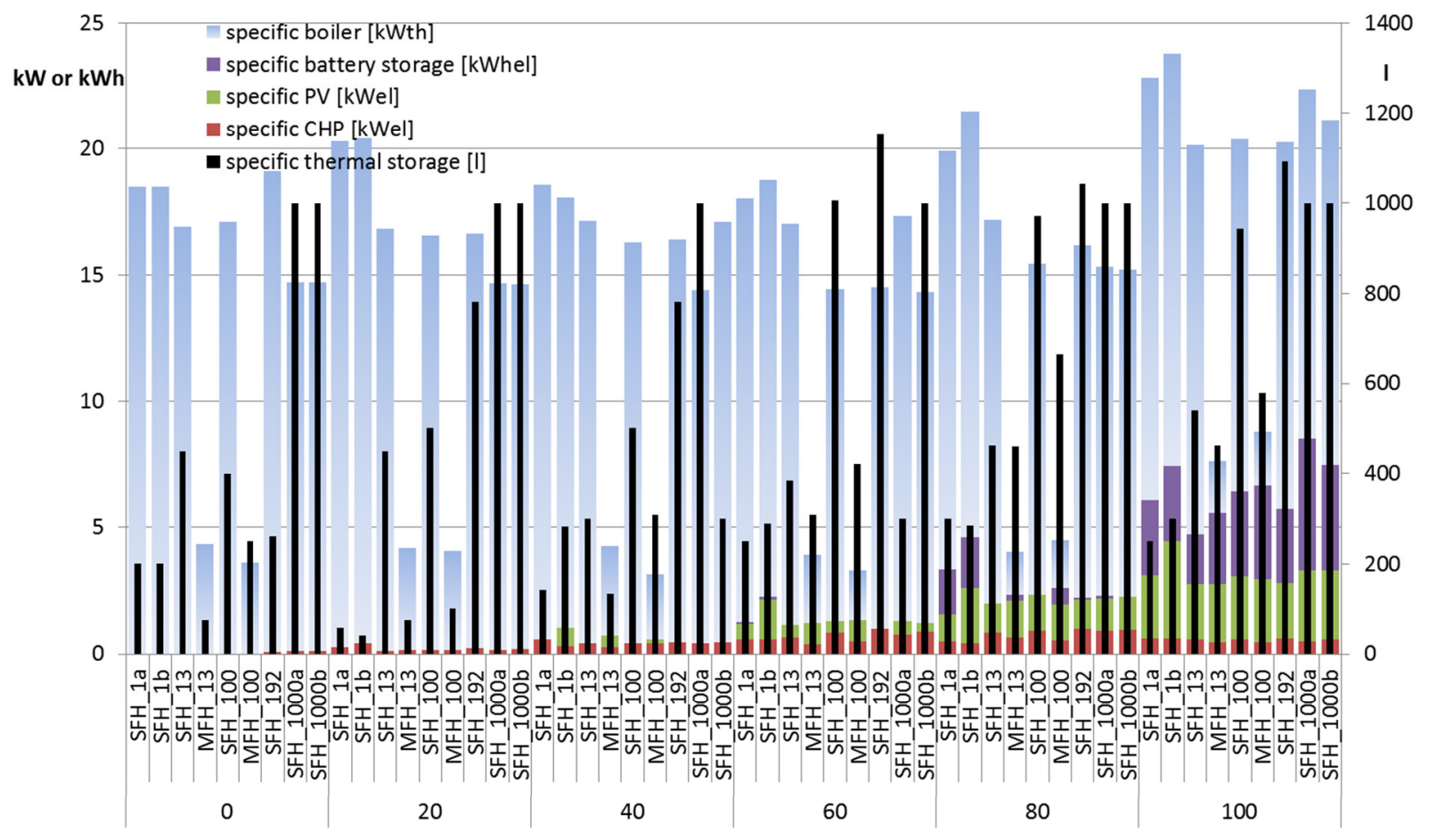

Figure 3: Overview of installed capacities for the nine studied cases and electrical selfsufficiencies $\left(D S S_{e l}\right)$ from $0 \%$ to $100 \%$

\subsection{Energy autonomy indicators}

Figure 4 shows the marginal change in total energy supply costs when increasing DSS $_{\mathrm{el}}$ from the optimum value (cf. Figure 2). Thereby for clarity only the cases that have an optimum level of selfsufficiency below $80 \%$ are shown. Increasing self-sufficiency from $30 \%$ to $60 \%$ for cases SFH_1a and SFH_1b, for example, seems to imply an overall cost increase of around $10 \%$. A similar but smaller cost increase is encountered when moving from $70 \%$ to $100 \%$ self-sufficiency as for case MFH_13. The gradient of the interpolated line could be used as a proxy for the marginal costs of increasing self-sufficiency for specific objects, but further data are required to validate this (see section 6).

Figure 5 below shows the a logarithmic curve fitted to the optimum degree of self-sufficiency for the nine cases analysed here (cf. Figure 2), against the number of households in each case. Note that two pairs of cases have the same number of households, so that only seven points are visible. The logarithmic curve fitted to (all of) the data points is also shown.

It is clear from the figure that the optimum level of self-sufficiency increases with the number of households. According to the curve fitted to the data, above 560 households it is economically advantageous to make a district $100 \%$ self-sufficient. On the other hand it is also possible to infer the number of households generally required to make a given level of self-sufficiency feasible, e.g. for $80 \%, 100$ households. 


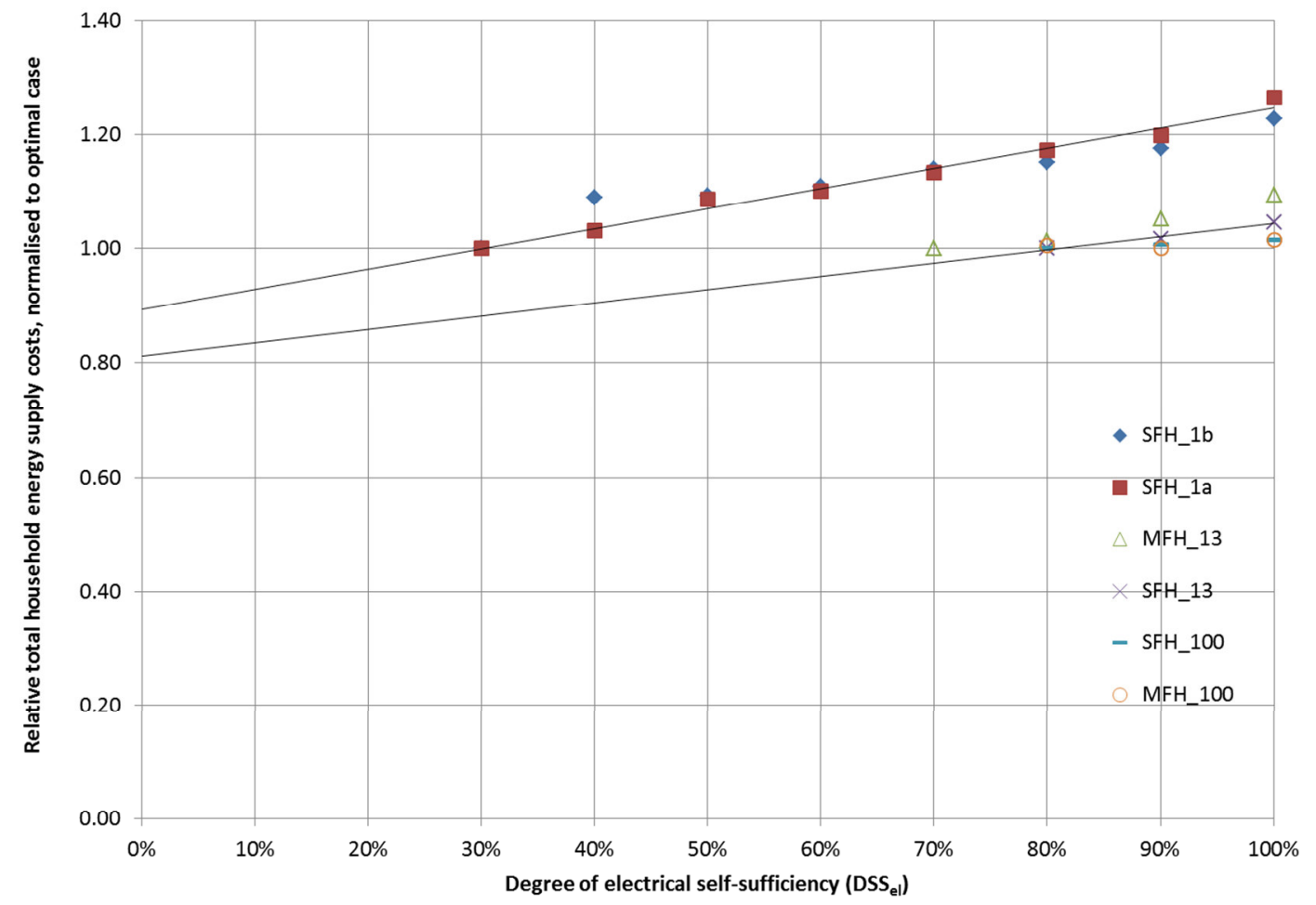

Figure 4: Marginal changes in total energy supply costs resulting from increasing electrical self-sufficiency from the optimum, for selected demand cases

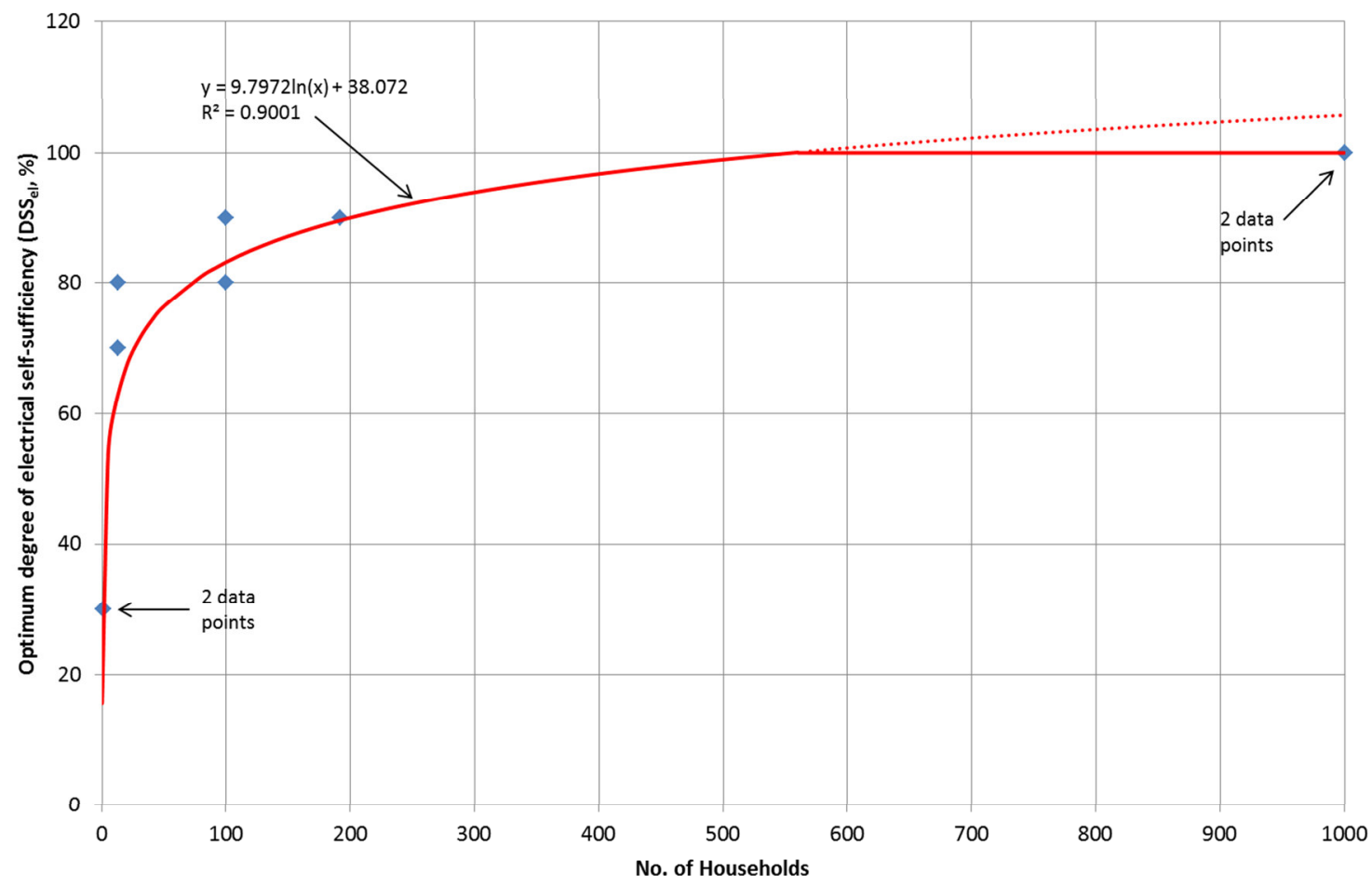

Figure 5: Optimum degree of electrical self-sufficiency against number of households for the nine demand cases, and a logarithmic curve fitted to these points 
The degree of electrical autonomy $\left(D A_{e l}\right)$ is shown plotted against the electrical degree of selfsufficiency $\left(D_{S S}\right)$ for selected demand cases in Figure 6 below. For the SFH demand cases the value of $\mathrm{DA}_{\mathrm{el}}$ is consistently higher than that of the $\mathrm{DSS}_{\mathrm{el}}$, lying to the upper left of the dashed line in the figure. In general, at higher scales such as $100 \mathrm{SFH}$ or $1000 \mathrm{SFH}$ and especially for the MFHs, the value of $\mathrm{DA}_{\mathrm{el}}$ is reduced and so is closer to the value of $\mathrm{DSS}_{\mathrm{el}}$. The reason for this is that at lower scales there is a higher mismatch between generation and load, so that in order to achieve a given level of $\mathrm{DSS}_{\mathrm{el}}$, relatively more electricity has to be generated and fed into the grid.

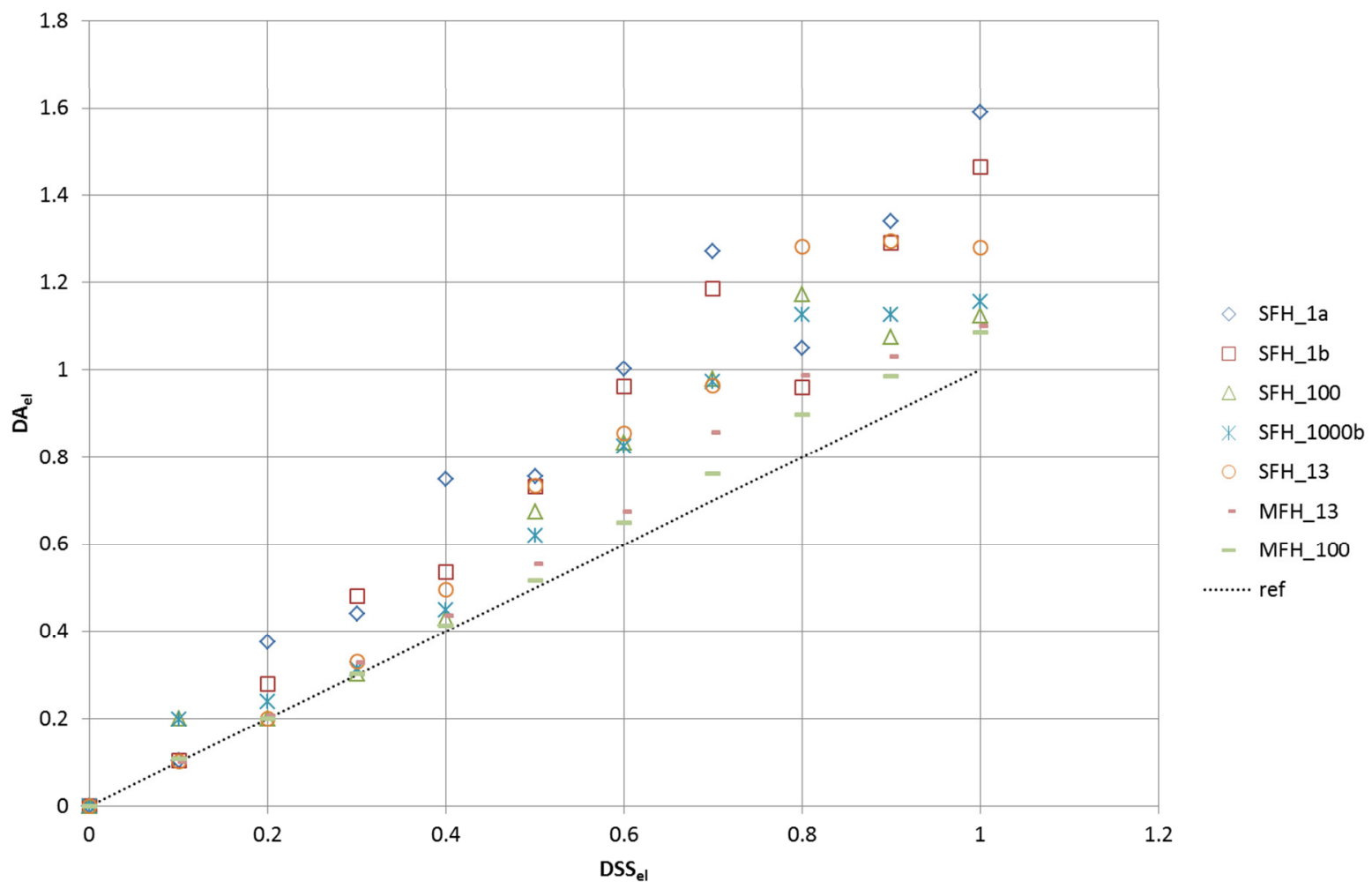

Figure 6: Degree of electrical autonomy $\left(D A_{e l}\right)$ against the electrical degree of self-sufficiency (DSS $S_{e l}$ for selected demand cases

Figure 7 below shows the Grid Interaction Index normalized to the value in the case of the input load profiles. The normalization results in a Gll close to unity in the case of the input load profile, as expected. Otherwise the Gll generally increases for a specific case with increasing levels of selfsufficiency. For some cases, especially SFH_1a and SFH_1b, the value of the GII is less than unity and decreases more at higher levels of self-sufficiency. The trend of increasing GII seems to reverse for most cases above about $70 \%$ self-sufficiency.

In addition, the minima of the residual load profiles ${ }^{4}$ become increasingly negative with increasing levels of self-sufficiency, whereas the maxima exhibit a slight reduction. The mean value of the residual load decreases with increasing levels of self-sufficiency, becoming negative between $50 \%$

\footnotetext{
${ }^{4}$ Defined here as the net household load from the perspective of the electricity network, positive being a import from the grid and negative being an export to it.
} 
and $90 \%$, depending on the case. With a few exceptions, the level of self-sufficiency at which the maximum negative mean value of the load occurs is $100 \%$ - for SFH_100 and SFH_192 this is $70 \%$.

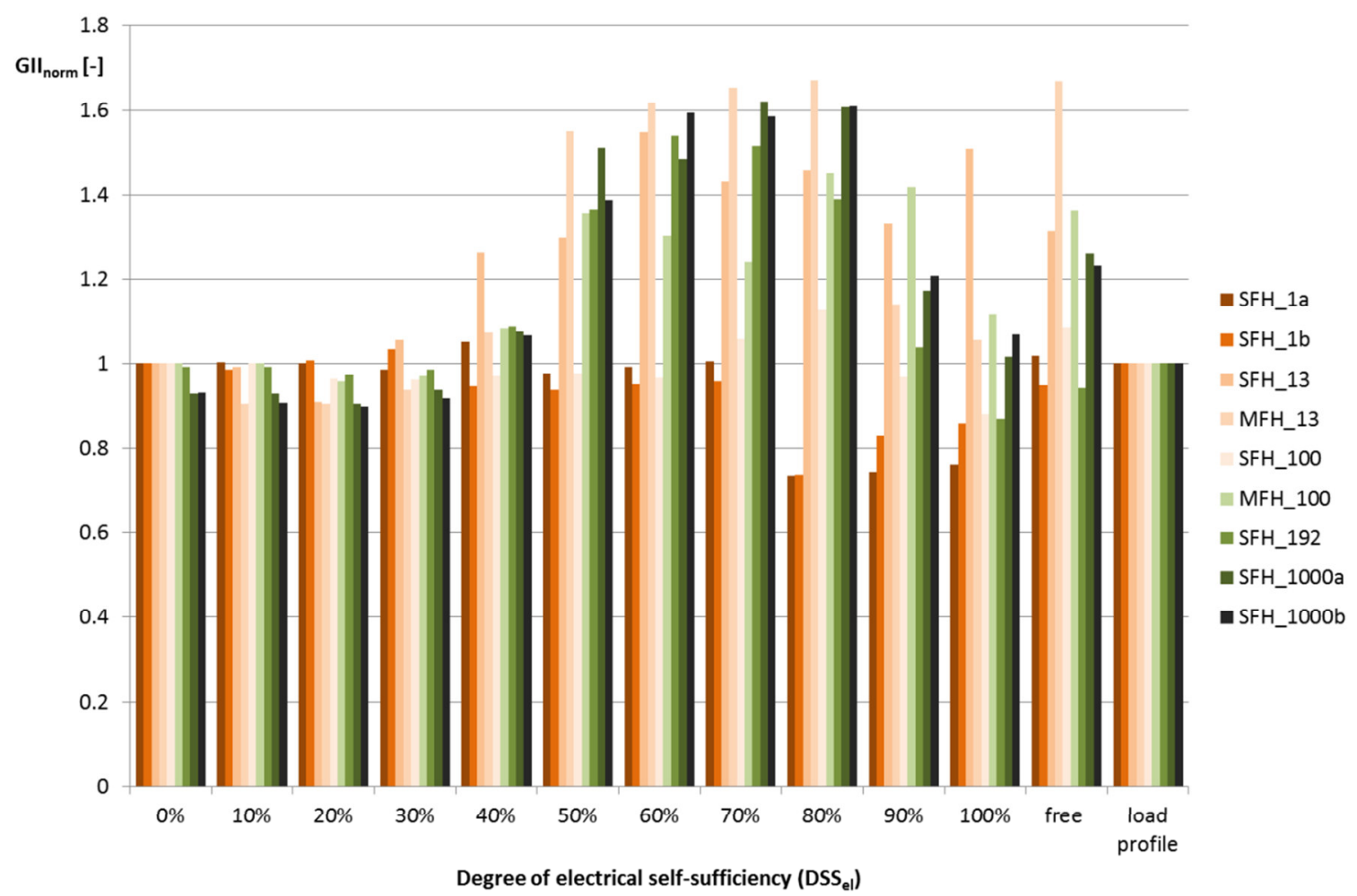

Figure 7: The nomalised Grid Interaction Index $\left(G I_{\text {norm }}\right)$ for the nine demand cases and all analysed levels of electrical self-sufficiency ("load profile" refers to the load profile for each of the cases, to which the GII is normalized)

\section{Discussion}

\subsection{Discussion of results}

The encountered effect, of decreasing total annual energy cost per household with increasing number of households, is mainly due to two reasons. On the one hand a larger number of households imply an increased demand for electricity and heat in absolute terms. As a result, the households benefit from economies of scale for the energy supply technologies (CHP unit, PV unit etc.) as also encountered for PV technologies by Baetens el al. (2012). As these are explicitly addressed in the optimization model (cf. section 3 ) they have a direct impact on the economic result.

On the other hand, the cost reduction also stems from two distinct but interrelated effects in the context of the aggregation of the electrical and thermal load curves according to the methodology set out in section 3. The first effect is a reduction in in demand fluctuation, a smoothing effect, as the stochastic nature of individual curves tend to cancel each other out, and the second is a 
reduction in peak load due to the superposition of the individual profiles (i.e. subadditivity). This can also be seen in Figure 7, whereby the demand cases at higher scales typically have lower values for the $\mathrm{Gll}_{\text {norm, }}$ irrespective of the level of electrical self-sufficiency. As a consequence the generating technologies can operate in a more uniform way, reaching a higher number of operating hours per year.

At larger scales, i.e. of neighbourhoods and districts, the economic case for higher levels of electrical self-sufficiency is given. However, the results indicate that high levels of electrical self-sufficiency are not economically attractive in individual buildings. But this insight only applies to existing buildings as considered here and furthermore is constrained to the supply side. It is likely that an additional consideration of demand side measures for energy efficiency and/or demand side management would modify the results encountered here. The former could be employed to reduce the overall energy demand of a building, e.g. through improved insulation, whereas the latter could reduce peak electricity loads and shift these towards times of (higher) on-site generation.

The main reason for neglecting these measures in the present case is due to constraints on model complexity; the existing model typically takes from hours up to days to solve on a standard desktop PC. Although energy efficiency measures are almost certainly a prerequisite for fully energyautonomous energy regions (Burgess et al. 2012), it is not thought that the general trend in the results identified here would be strongly affected by considering energy efficiency. Instead the technologies would be dimensioned smaller and the annual energy supply costs would be accordingly lower. But there is no substantial scale effect associated with energy efficiency measures, i.e. the potential for demand reduction in ten identical buildings is ten times the potential in one of the buildings. The scope of DSM, on the other hand, could well exhibit some scale effects, such that for example there is a threshold number of households/buildings that should be supplied and networked together in order to exploit their combined DSM potentials. But DSM is considered a research area in itself so that such analyses must remain out of scope in the present case.

The observed trend in the Gll norm seems largely to be due to a shift in installed technologies. A comparison of Figure 3 and Figure 7 suggests that the reduction in this indicator at higher levels of electrical self-sufficiency is due to the installation of battery storage capacities. If the objective is to minimize this indicator, e.g. in order to minimize the level of interaction of individual buildings with the electrical distribution networks, then either a very low or a very high level of electrical selfsufficiency per household could be envisioned. At scales above the individual building the associated marginal costs of increasing the electrical self-sufficiency are lower than those for individual buildings (Figure 4). This implies that, for a given level of electrical self-sufficiency, even for SFHs there are significant economic benefits to be gained from combining the energy supply systems of several objects.

Comparing the results with those in the literature highlights some similar findings. At higher scales of aggregation and levels of electrical self-sufficiency all of the technologies have much larger capacities. This applies especially to the storage units, without which these self-sufficiency levels could not be reached (e.g. Comodi et al. 2015, Orehouning et al. 2015). The assertion in the literature, that the currently high specific investment in batteries is a constraining factor for their deployment is confirmed here at the building level. But at the neighbourhood and district levels the exploitation of this technology to achieve higher levels of electrical self-sufficiency and the same time lower overall costs suggests that there are substantial economic benefits from aggregating 
demand objects in this way. On the other hand, the higher energy supply costs encountered by Jenssen et al. (2010) and Schmidt et al. (2012) were not realized here, which is most likely due to not considering biomass-based energy supply.

The analysis thus far has mainly focused on microeconomic (costs) and technical aspects (capacities, generation, grid interaction). There are of course other dimensions relating to the discussion surrounding energy autonomy, for example environmental and macroeconomic to name a few. Due to the nature of the energy supply systems analysed here, along with the emissions credits apportioned for displacing grid electricity, the results relating to $\mathrm{CO}_{2}$ emissions are somewhat unremarkable. These emissions decrease approximately linearly with increasing levels of electrical self-sufficiency, from a maximum at $0 \%$ to a minimum at $100 \%$ and lying in the region of $6-8 \mathrm{tCO} / \mathrm{a}$ for SFHs and 2.0-5.5 tCO2/a for MFHs. The shift of technology away from boilers, towards mCHP, PV and batteries (in that order, cf. Figure 3 ) results in lower specific $\mathrm{CO}_{2}$ emissions and a higher credit for displaced grid electricity. Hence from the perspective of $\mathrm{CO}_{2}$ emissions a high level of electrical self-sufficiency would be advantageous.

From a macroeconomic perspective there are economic inefficiencies that would arise from a large number of households attempting to achieve high(er) levels of electrical autonomy. For example, if communities increase their local renewable energy supply and thereby reduce their use of local electricity networks, the consumers thereby contribute less to the overall network costs, as these are charged as a surcharge for all end-consumer (with some exceptions) per unit of electricity purchased. ${ }^{5}$ However, the total network costs are only marginally changed by this single community project, so that the charges for remaining consumers who exploit the network as much as previously have to be increased. In addition, Jägemann et al. (2013) find that, whilst there are clear benefits to the consumers from increased levels of electrical self-sufficiency, the net effect on a system level includes substantial additional costs. Furthermore, they highlight the redistributional effects, which lead to a higher relative financial burden on all other households, i.e. those not striving for higher energy autonomy. In relative terms, the burden falling on poorer households would be larger. They suggest abolishing the financial incentive for in-house PV electricity consumption and moving to a system of network fees based on the amount of capacity instead of energy utilized.

Under the current energy-political framework in Germany it is likely that, even without this financial incentive on in-house PV electricity consumption, with lower specific investments in batteries in coming years, the maximization of in-house consumption will become economically attractive. The cost of generation and storage of this electricity would still lie significantly below the cost of electricity for end users, currently at around $30 € \mathrm{ct} / \mathrm{kWh}$. Hence unless this own-generated electricity was subject to the same levies and taxes as the electricity from the network, the distortion (inefficiency) pointed out above would still remain.

This problem stems from the requirement of households to take advantage of the electricity supply infrastructure for a (decreasing) number of hours per year (with increasing levels of electrical selfsufficiency). Even if the electrical self-sufficiency is $100 \%$ on balance, as analysed here, the households will still utilize the network, for example to feed in excess generation. Only in the case of a completely energy-autonomous neighbourhood or district would the connection to the network

\footnotetext{
${ }^{5}$ It should also be noted that there is a current and ongoing discussion about capacity markets in a European context, which could mean that network fees are partly or wholly charged according to the amount of capacity, and not energy, utilized.
} 
become unnecessary. But other studies have demonstrated that a completely autonomous energy supply based on high proportions of renewables and low carbon technologies requires enormous storage capacities (Rodrigues et al. 2014). Whilst being technically feasible it is currently far from being economically attractive.

\subsection{Sensitivity analysis}

A sensitivity analysis is carried out to investigate the effects of changing one input parameter at a time on the results. Two scenarios are distinguished, namely one involving the assumptions detailed in section 3 for 2015 and one hypothetical scenario for 2020. The latter assumes an electricity price for households of $37 € \mathrm{ct} / \mathrm{kWh}$ (compared to $29 € \mathrm{ct} / \mathrm{kWh}$ ), an absence of any feed-in tariffs for CHP or PV electricity and a reduction in the specific investment for PV and batteries from 100\% in 2015 to $75 \%$ in 2020 (cf. section 3).

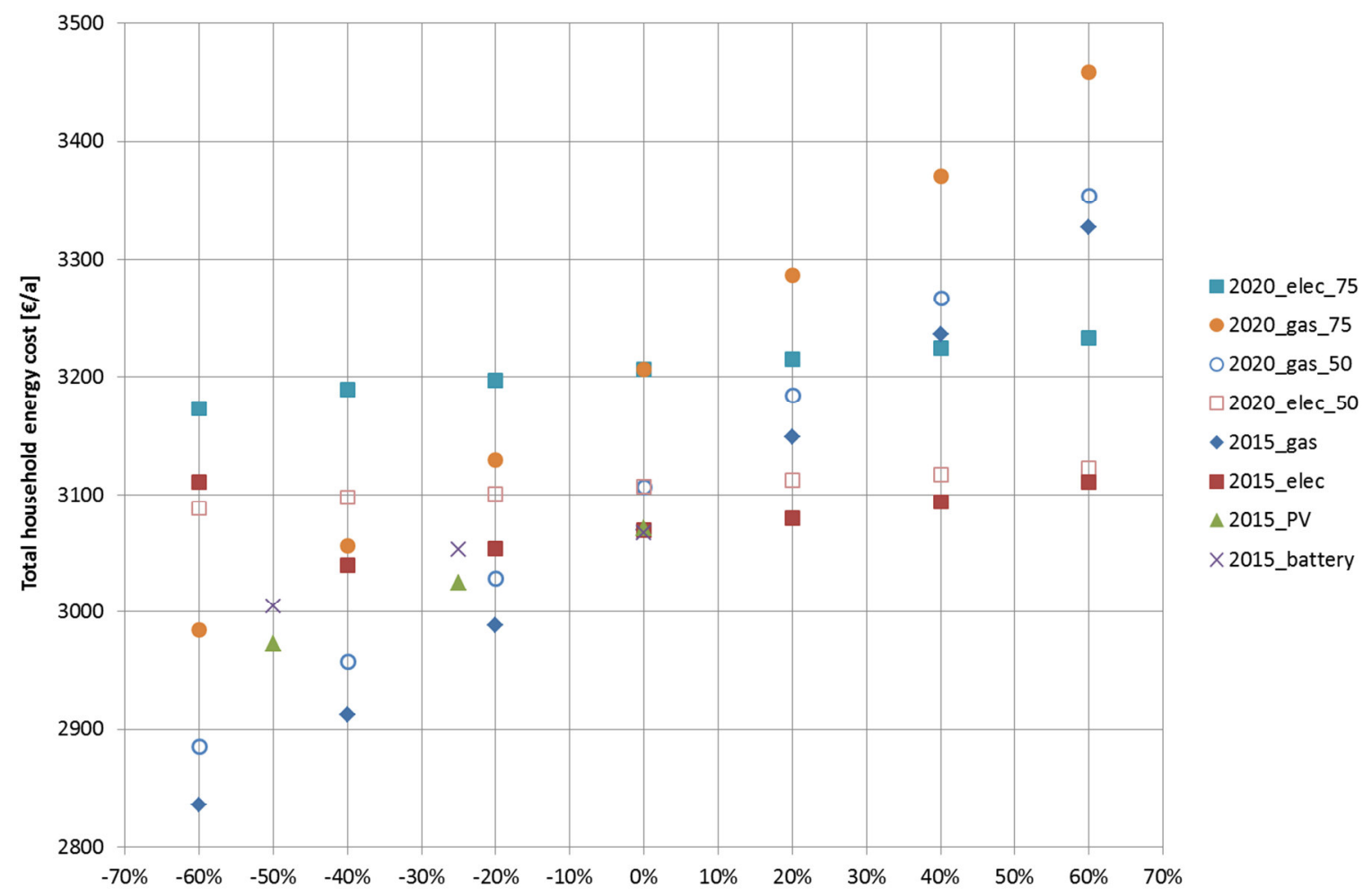

Figure 8: Sensitivity analysis of total household annual energy costs to specific investments of PV and battery storage, gas and electricity prices, and feed in tariffs

Figure 8 shows the results of this sensitivity analysis, whereby the percentage change in the respective input parameter on the $\mathrm{x}$-axis results in the corresponding total annual household energy costs on the y-axis. In general, there is a very weak sensitivity of these costs to the electricity price: a $60 \%$ change in the latter results in less than $1 \%$ change in the former. In contrast, there is a much stronger sensitivity to the gas price: a $60 \%$ change in the latter results in a $7 \%$ change in the former. Changing the specific investments for PV and batteries leads to, ceteris paribus, lower energy supply 
costs. Hereby the strongest sensitivity is to the former, whereby a $50 \%$ reduction results in a $3 \%$ reduction in annual costs. The "2020 scenario" results in a shift in the total annual costs in the reference case from around $3050 € / a$ to about $3200 € / a$.

In terms of the installed technologies, the technology mix is only weakly sensitive to these assumptions. The exception here is the battery storage, for which all combinations of gas and electricity price variations, other than the "-40\%" electricity price, result in negligible capacity being installed. The variation of the specific investment for PV and batteries has a much stronger effect. Hence both battery storage and PV capacities are strongly dependent on the cost of battery storage, whereas the cost of PV has a less significant effect. The capacity of the thermal storage unit changes dramatically with these variations, as the dimensioning of the CHP unit is adjusting according to different PV and battery capacities. In the 2020 scenario, electricity prices from $-40 \%$ to $-60 \%$ result in no battery storage being installed and slightly lower PV capacities, which are compensated for with CHP capacities.

\subsection{Critique and suggestions for further work}

This section highlights some of the weakness in the employed approach, including uncertainties and assumptions relating to the model input, as well as aspects not or only partly considered that remain a focus for further work.

As demonstrated in the previous subsection, the optimization model presented in section 3 is sensitive to varying degrees to the input parameters, especially the specific investment in technologies and gas/electricity prices. Whilst an attempt has been made to ensure that the employed data represent the current status, there certainly remains a degree of uncertainty relating to their development into the future. The tendency of the results due to changes in these input parameters has been shown above, so the main points to raise here relate to the model approach itself. The model has perfect foresight and the conditions (e.g. thermal and electrical demand pattern, climate) are the same for each of the years within the planning horizon of 20 years with the exception of the evolution of the prices of the energy carriers. Hence the model is unable to account for sudden "shocks" such as extreme climate events or price spikes that might occur and lead to drastically different results. The employed technologies are dimensioned for these load profiles, which remain the same for 20 years, so the determined capacities are most likely to be different to those determined based on other climatic years or user behaviour (e.g. economic crisis). However, as this applies to all technologies and demand cases analysed here, and the relative rather than the absolute results are of interest, the effect on the overall trend is thought to be negligible.

The scope of the analysis could also be criticized along the following lines:

- Socioeconomic dimensions of domestic energy use: many studies have demonstrated the importance of these aspects in influencing the demand side, but the only differentiation considered here is in terms of the number of people per household.

- Sector: only the domestic sector was investigated in this study, but the commercial sector, due to having higher and more constant electrical demand profiles through the daytime, is much better suited to integrating larger amounts pf PV-generated electricity. 
- Supply-side focus: the focus was on the energy supply systems for the buildings considered rather than any demand side measures, including energy efficiency and DSM, which could reduce the overall demand and thus increase the energy autonomy.

- Technologies: only a selection of low-carbon technologies suitable for residential applications was considered. For example, other technologies such as heat pumps could also be employed alongside $\mathrm{mCHP}$ to provide flexibility and integrate renewable electricity (Fehrenbach et al. 2014).

- Network aspects: the approach employed here assumes that the local energy (electricity and heat) infrastructure is able to assimilate the respective energy flows. In practice there is clearly a capacity constraint on these energy flows, which should be considered to more accurately depict reality.

Whilst these aspects remain beyond the scope of the current contribution, they should and will be addressed in further work.

\section{Summary and conclusions}

Against the background of increasing decentralized energy supply structure and economic incentives for increasing the level of self-generation and -consumption, this paper analyses the scale effects on the economics of energy autonomy in residential buildings. A model-based assessment of the economically optimum level of energy autonomy for residential buildings at five scales of aggregation is carried out. The employed model is a mixed integer linear program (MILP) that minimizes the total system costs over the lifetime of the investigated energy system (20 years) subject to several constraints, amongst other things the degree of electrical self-sufficiency. The model has been extended beyond previous contributions to consider PV and battery storage technologies and is applied to nine demand cases. The latter consist of a combination of building types, number of households and number of occupants, based on German national statistics.

The results indicate a shift in the economically optimal level of electrical self-sufficiency with scale. In SFHs this means from around $30 \%$ at the individual building level to almost $100 \%$ in districts of 1000 SFH households. For MFHs the trend is similar but less pronounced, with a shift from $72 \%$ to $87 \%$ between 13 and 100 households. This suggests that, under the given energy-political framework conditions in Germany, above around 560 households it could be economically advantageous to make districts of residential buildings electrically self-sufficient. In addition, a marginal increase in electrical self-sufficiency is significantly more expensive at lower aggregation scales (i.e. single buildings) compared to the scale of neighbourhoods and districts. The level of interaction with the electrical distribution network increases with increasing electrical self-sufficiency before then decreasing at very high (above $70 \%$ ) levels.

The focus of this research on the supply side in existing residential buildings presents several avenues for future work, including:

- Employing a richer socioeconomic differentiation between households. 
- Considering other sectors such as the commercial sector which has a demand profile with a much better temporal match to PV generation.

- Incorporateing demand side options including energy efficiency measures and DSM.

- Modelling other technologies at the heat/electricity interface such as heat pumps.

- Analysing the effects on the electrical distribution networks.

It is clear that there are some competing objectives in the context of scaling energy autonomy in residential buildings. In economic terms it is important to distinguish the micro- from the macroeconomic perspectives. The former represents an incentive for increased energy autonomy at higher scales of aggregation, whereas the latter discourages it completely due to the resulting increased total costs and unequal burden sharing. In terms of $\mathrm{CO}_{2}$ emissions, the results here suggest increasing energy autonomy is favourable, but in a similar way to the economic effects, this is only valid at the margin; as soon as all large numbers of neighbourhoods attempt this, the average electricity mix is affected and the displaced electricity is no longer associated with the same credits. Finally, from an electricity network perspective it seems that either very low or very high levels of energy autonomy should be advantageous. Hence one further key question relates to the implications of higher levels of energy autonomy at different scales on the whole energy system.

\section{References}

Baetens, R., De Coninck, R., Van Roy, J., Verbruggen, B., Driesen, J., Helsen, L., Saelens, D., 2012. Assessing electrical bottlenecks at feeder level for residential net zero-energy buildings by integrated system simulation. Applied Energy, 96, 74-83.

Briano, José Ignacio; Báez, María Jesús; Morales, Rocío Moya (2015): CREARA PV Grid Parity Monitor. Residential Sector. Hg. v. Creara, http://www.leonardo-energy.org/sites/leonardoenergy/files/documents-and-links/pv grid parity monitor - residential sector - issue 3.pdf, last checked on 29.10.2015.

Bundesministerium für Wirtschaft und Energie (BMWi, 2014), Monitoring-Bericht nach $\S 51$ EnWG zur Versorgungssicherheit im Bereich der leitungsgebundenen Versorgung mit Elektrizität, BMWi, Bonn.

Burgess, P. J., Casado, M. R., Gavu, J., Mead, A., Cockerill, T., Lord, R., Van der Horst, D., Howard, D. C., 2012. A framework for reviewing the trade-offs between, renewable energy, food, feed and wood production at a local level. Renewable and sustainable energy reviews, 16(1), 129-142.

Comodi, G., Giantomassi, A., Severini, M., Squartini, S., Ferracuti, F., Fonti, A., Cesarini, D., Morodo, M., Polonara, F., 2015. Multi-apartment residential microgrid with electrical and thermal storage devices: Experimental analysis and simulation of energy management strategies. Applied Energy, $137,854-866$.

De Coninck, R., Baetens, R., Saelens, D., Woyte, A., Helsen, L., 2014. Rule-based demand-side management of domestic hot water production with heat pumps in zero energy neighbourhoods. Journal of Building Performance Simulation, 7(4). 
EuPD Research (2014). Storage Price Tool. Bonn.

International Energy Agency (IEA, 2012): World Energy Outlook 2012: OECD Publishing. Paris.

Jägemann, C., Hagspiel, S., Lindenberger, D., 2013. The economic inefficiency of grid parity: The case of German photovoltaics, EWI Working Paper No 13/19, December 2013.

Jenssen, T., König, A., Eltrop, L., 2014. Bioenergy villages in Germany: Bringing a low carbon energy supply for rural areas into practice. Renewable Energy, 61, 74-80.

Klaus Novy Institut e.V. \& trend:research (2011), "Marktakteure: Erneuerbare-Energien-Anlagen in der Stromerzeugung", Köln.

Killinger, S., Mainzer, K., McKenna, R., Kreifels, N., Fichtner, W. (2015): A regional optimisation of renewable energy supply from wind and photovoltaics with respect to three key energy-political

Klein, S.A., Beckman, W.A., Mitchell, J.W., Duffie, J.A., Duffie, N.A., Freeman, T.L., et al., 2010. TRNSYS 17 - a transient system simulation program . user manual. Solar Energy Laboratory, University of Wisconsin-Madison.

Marino, C., Nucara, A., Pietrafesa, M., Pudano, A., 2013. An energy self-sufficient public building using integrated renewable sources and hydrogen storage. Energy, 57, 95-105.

McKenna, R., Merkel, E., Fehrenbach, D., Mehne, S., Fichtner, W., 2013, Energy efficiency in the German residential sector: a bottom-up building-stock-model-based analysis in the context of energy-political targets, Building and Environment, 62, 77-88

Merkel, E., McKenna, R., Fichtner, W., 2015. Optimisation of the capacity and the dispatch of decentralised micro-CHP systems: a case study for the UK, Applied Energy, 140, 120-134.

Milan, C., Bojesen, C., Nielsen, M., 2012. A cost optimization model for $100 \%$ renewable residential energy supply systems. Energy, 48(1), 118-127.

Mondol, J. D., Yohanis, Y. G., Norton, B., 2009. Optimising the economic viability of grid-connected photovoltaic systems. Applied Energy, 86, 985-999.

Müller, M. O., Stämpfli, A., Dold, U., Hammer, T. (2011): Energy Autarky: A conceptual framework for sustainable regional development. In: Energy Policy, 39, S. 5800-5810.

Orehounig, K., Evins, R., Dorer, V., 2015. Integration of decentralized energy systems in neighbourhoods using the energy hub approach. Applied Energy, 154, 277-289.

Rae, C., \& Bradley, F. (2012): Energy autonomy in sustainable communities - A review of key issues. In: Renewable and Sustainable Energy Reviews, 16, S. 6497-6506.

Remund, J., Müller, S., Kunz, S., Huguenin-Landl, B., Studer, C., Klauser, D., Schilter, C., Lehnherr, R. (2014): meteonorm - Global Meteorological Database. Handbook Part I: Software. Bern: METEOTEST.

Rodrigues, E.M.G., Godina, R., Santos, S.F., Bizuayehu, A.W., Contreras, J., Catalao, J,P.S., 2014, Energy storage systems supporting increased penetration of renewables in islanded systems, Energy, $75,265-280$. 
Salom, J., Widén, J., Candanedo, J., Sartori, I., Voss, K., Marszal, A., 2011, November. Understanding net zero energy buildings: evaluation of load matching and grid interaction indicators. In proceedings of building simulation (Vol. 6, pp. 2514-2521).

Schmidt, J., Schönhart, M., Biberacher, M., Guggenberger, T., Hausl, S., Kalt, G., Leduc, s., Schardinger, I., Schmid, E., 2012. Regional energy autarky: Potentials, costs and consequences for an Austrian region. Energy Policy, 47, 211-221.

Statistisches Bundesamt, 2008. Bauen und Wohnen, Mikrozensus Zusatzerhebung 2006, Bestand und Struktur der Wohneinheiten, Wohnsituation der Haushalte, Fachserie 5/Heft 1. Wiesbaden.

Statistisches Bundesamt 2013. Wirtschaftsrechnungen: Einkommens- und Verbrauchsstichprobe Wohnverhältnisse privater Haushalte, Fachserie 15, Sonderheft 1, Wiesbaden.

Telléz Molina, M.B., Pradanović, M., 2013. Profitability assessment for self-sufficiency improvement in grid-connected non-residential buildings with on-site PV installations, Paper at the IEEE Clean Electrical Power Conference (ICCEP) 2013, Alghero, Italy, June 2013.

VDI, 2008. Reference load profiles of single-family and multi-family houses for the use of CHP systems, guideline 4655. The Association of German Engineers.

Walker, G. 2008. What are the barriers and incentives for community-owned means of energy production and use? Energy Policy, 36, 12, 4401-4405

Weniger, J., Tjden, T., Quaschning, V., 2013. Sizing of residential PV battery systems. Energy Procedia $46,78-87$.

Widén, J., Wäckelgård, E., Lund, P.D., 2009. Options for improving the load matching capability of distributed photovoltaics: Methodology and application to high-latitude data. Solar Energy, 83, 1953-1966. 


\section{Working Paper Series in Production and Energy}

recent issues

No. 1 Alexandra-Gwyn Paetz, Lisa Landzettel, Patrick Jochem, Wolf Fichtner: Eine netnografische Analyse der Nutzererfahrungen mit E-Rollern

No. 2 Felix Teufel, Michael Miller, Massimo Genoese, Wolf Fichtner: Review of System Dynamics models for electricity market simulations

No. 3 Patrick Jochem, Thomas Kaschub, Wolf Fichtner:

How to integrate electric vehicles in the future energy system?

No. 4 Sven Killinger, Kai Mainzer, Russell McKenna, Niklas Kreifels, Wolf Fichtner

A regional simulation and optimisation of renewable energy supply from wind and photovoltaics with respect to three key energy-political objectives

No. 5 Kathrin Dudenhöffer, Rahul Arora, Alizée Diverrez, Axel Ensslen, Patrick Jochem, Jasmin Tücking

Potentials for Electric Vehicles in France, Germany, and India

No. 6 Russell McKenna, Carsten Herbes, Wolf Fichtner:

Energieautarkie: Definitionen, Für-bzw. Gegenargumente, und entstehende Forschungsbedarfe

No. 7 Tobias Jäger, Russell McKenna, Wolf Fichtner:

Onshore wind energy in Baden-Württemberg: a bottom-up economic assessment of the socio-technical potential

No. 8 Axel Ensslen, Alexandra-Gwyn Paetz, Sonja Babrowski, Patrick Jochem, Wolf Fichtner:

On the road to an electric mobility mass market - How can early adopters be characterized?

No. 9 Kai Mainzer, Russell McKenna, Wolf Fichtner:

Charakterisierung der verwendeten Modellansätze im

Wettbewerb Energieeffiziente Stadt

No. 10 Hannes Schwarz, Valentin Bertsch, Wolf Fichtner:

Two-stage stochastic, large-scale optimization of a decentralized

energy system - a residential quarter as case study

No. 11 Russell McKenna, Erik Merkel, Wolf Fichtner:

Development of a multi-energy residential service demand model for evaluation of prosumers' effects on current and future residential load profiles for heat and electricity

The responsibility for the contents of the working papers rests with the author, not the institute. Since working papers are of preliminary nature, it may be useful to contact the author of a particular working paper about results or caveats before referring to, or quoting, a paper. Any comments on working papers should be sent directly to the author. 


\section{Impressum}

Karlsruher Institut für Technologie

Institut für Industriebetriebslehre und Industrielle Produktion (IIP) Deutsch-Französisches Institut für Umweltforschung (DFIU)

Hertzstr. 16

D-76187 Karlsruhe

KIT - Universität des Landes Baden-Württemberg und nationales Forschungszentrum in der Helmholtz-Gemeinschaft

Working Paper Series in Production and Energy

No. 11, February 2016

ISSN 2196-7296 